\title{
Fractures in the elderly: when is hip replacement a necessity?
}

\author{
This article was published in the following Dove Press journal: \\ Clinical Interventions in Aging \\ 17 December 2010 \\ Number of times this article has been viewed
}

\section{Prasad Antapur \\ Nizar Mahomed \\ Rajiv Gandhi}

Toronto Western Hospital, Toronto, Ontario, Canada
Correspondence: R Gandhi Department of Orthopaedics, Toronto Western Hospital, 399 Bathurst Street, Toronto, Ontario M5T 2S8, Canada

Tel + I 4166035800 ext 5642

Fax + I 4166033437

Email rajiv.gandhi@uhn.on.ca

\begin{abstract}
As the world's population ages, hip fractures pose a significant health care problem. Hip fractures in the elderly are associated with impaired mobility, and increased morbidity and mortality. Associated conditions, such as osteoporosis, medical comorbidity, and dementia, pose a significant concern and determine optimal treatment. One-year mortality rates currently range from $14 \%$ to $36 \%$, and care for these patients represents a major global economic burden. The incidence of hip fractures is bimodal in its distribution. Young adult hip fractures are the result of high energy trauma, and the larger peak seen in the elderly population is secondary to low-energy injuries. The predilection for the site of fracture at the neck of femur falls into two major subgroups. Pertrochanteric fractures occur when the injury is extracapsular and the blood supply to the head of femur is unaffected. The management of this group involves internal fixation through a sliding hip screw device or intramedullary fixation device, both of which have good results. The other group of patients who sustain an intracapsular fracture at the femoral neck are at increased risk of nonunion and osteonecrosis. Recent papers in the literature have shown better functional outcomes with a primary hip replacement over other treatment modalities. This article reviews the current literature and indications for a primary total hip replacement in these patients.
\end{abstract}

Keywords: hip fractures, elderly, hip replacement

\section{Introduction}

As the world's population ages, hip fractures pose a significant health care problem. Hip fractures in the elderly are associated with impaired mobility, poor balance, delayed reaction times, and compromised vision. ${ }^{1}$ Associated conditions such as osteoporosis, medical comorbidity, and dementia pose a significant concern. One-year mortality rates currently range from $14 \%$ to $36 \% .^{2-4}$ Care for these patients represents a major global economic burden. ${ }^{5}$ Selection of treatment is determined by the general physical and mental capacity of these patients.

\section{Epidemiology}

In 1996, the US Department of Health and Human Services reported approximately 340,000 hip fractures annually in the US alone, with $90 \%$ of fractures occurring in people older than 65 years. ${ }^{6}$ Worldwide, numbers of elderly people are projected to double by the year 2040, portending a substantially increased hip fracture burden on public health care systems. The growth of the elderly population is predicted to be more marked in Latin America, Asia, the Middle East, and Africa, compared with Europe and North America. ${ }^{7}$ submit your manuscript $\mid$ www.dovepress.com

Dovepress

DOI: $10.2147 /$ CIA.S10204
Clinical Interventions in Aging 201 I:6 I-7

(C) 201 I Antapur et al, publisher and licensee Dove Medical Press Ltd. This is an Open Access article which permits unrestricted noncommercial use, provided the original work is properly cited. 
The incidence of hip fractures is bimodal in its distribution. Young adult hip fractures are generally the result of high-energy trauma, and the larger peak seen in the elderly population is secondary low-energy injuries. ${ }^{8}$ It is estimated that the lifetime risk for hip fractures is $23.3 \%$ for men and $11.2 \%$ for women. ${ }^{9}$

Elderly people are prone to frequent falls secondary to poor balance, physical illness, medications, deteriorating vision, and environmental hazards. ${ }^{10}$ Lack of protective mechanisms, such as use of the hands to break a fall and lack of coordination contribute to the increased incidence of fractures in the elderly. Associated reduction in bone mineral density also contributes to the risk of fractures.

The use of hip protector pads has had mixed results. These devices consist of a contoured plastic or foam shield which can be worn in specially designed pockets in the underwear. The pad is designed to absorb or dissipate energy and is placed over the greater trochanter. ${ }^{11,12}$ Conflicting reports exist on the efficacy of hip protector pads in reducing the incidence of hip fractures. ${ }^{13-15}$ The use of hip protectors has been shown to reduce the incidence of hip fractures in nursing home residents, possibly due to increased compliance. ${ }^{15}$

\section{Financial burden}

Numerous reports exist in the literature looking at the financial burden of a fractured hip. ${ }^{16-18} \mathrm{~A}$ typical patient spends US $\$ 40,000$ in the first year following hip fracture on direct medical costs and almost US $\$ 5000$ in subsequent years. ${ }^{19-21}$ Reports from Europe suggest that the average cost for treatment following a hip fracture is $€ 20,000 .{ }^{22}$ The financial burden of loss of employment of family members and caregiver burden has not been included in these analyses. Annual health care spending for hip fractures in the US is estimated to be more than US $\$ 15$ billion. ${ }^{17}$ This places an enormous burden on orthopedic teams to ensure that the optimal treatment is selected to ensure a quick return to preinjury level of function with minimal reoperation rates in these patients. ${ }^{23}$

\section{Classification and management options}

The goals of management in these patients are well recognized, ie, pain relief, early mobilization, accelerated rehabilitation to preinjury levels, and maintenance of an independent lifestyle. Fractures of the proximal femur occur in two anatomically distinct regions. Pertrochanteric and subtrochanteric fractures are more likely to occur in patients with a previously stiff hip secondary to arthritis. The fracture is extracapsular and the blood supply to the femoral head is well preserved. These fractures can be treated with a cephalomedullary nail or a sliding hip screw device as the primary operative fixation method. This allows the patients to mobilize early and carries a low risk of osteonecrosis.

Intracapsular fractures can be classified into displaced or undisplaced femoral neck fractures. The risk of osteonecrosis is lower following undisplaced fractures. ${ }^{24}$

Displaced intracapsular fractures are associated with osteoporosis and with an increased incidence of osteonecrosis. Because the blood supply to the head of the femur is likely to be damaged, treatment options include internal fixation, hemiarthroplasty, and total hip arthroplasty. The ideal choice of operative treatment depends on the general physical condition and mental capacity of the patient.

Compelling evidence is now available to suggest that total hip arthroplasty is the treatment of choice in patients who are biologically fit.

Postoperative rehabilitation has been shown to reduce hospital stay and medical complications, improve functional outcome, reduce admissions to nursing homes, and help elderly patients return to their preinjury mobility state..$^{25,26}$ Various strategies, including treadmill gait training and quadriceps muscle neurostimulation, have been used. Binder et al compared low intensity training and extended rehabilitation with progressive resistance exercises in a community setting and concluded that there was better physical function, quality of life, and reduced disability in the extended group. ${ }^{27} \mathrm{Hal}-$ bert et al, in their review of 11 randomized controlled trials, concluded that $16 \%$ of people are less likely to have a poor outcome, defined as death or admission to nursing home, after multidisciplinary postoperative rehabilitation supervised by a rehabilitation physician or a geriatrician, as compared with standard orthopedic rehabilitation. ${ }^{28}$

In addition to the fracture, attention should also be directed to overall care, including associated medical conditions, such as anemia, chest infection, and urinary tract infections. Many of these elderly patients also have previously undiagnosed cardiac problems, the presence of which may alter the surgical options. Dementia is another significant comorbidity which affects the surgical options and outcome. The role of the geriatrician is invaluable in reducing the complications from medical comorbidity.

\section{Undisplaced fractures}

Debate exists about the need for operative management of undisplaced intracapsular fractures. Elderly patients with medical comorbidities that place them at high risk for anesthesia and surgery-related complications can 
be managed nonoperatively. Venous thromboembolism prophylaxis and skin care is recommended in these patients to avoid pressure ulcer formation. ${ }^{29}$

Nonambulatory patients and patients suffering from severe dementia who have minimal discomfort may also be treated nonoperatively. The risk of displacement of these fractures has been reported in the literature at about $20 \%{ }^{30}$ Valgus impacted fractures of the femoral neck are stable injuries that can be managed nonoperatively. The advantages of surgical fixation for nondisplaced fractures are early patient mobilization and minimal risk of subsequent displacement of a nondisplaced fracture. Raaymakers and Marti reported an $86 \%$ union rate in their study of 170 consecutive patients with impacted femoral neck fractures who were treated with early mobilization and weight bearing. Patients older than 70 years and in poor general health had the highest rate of secondary displacement. ${ }^{30}$

Conn and Parker examined 375 patients with nondisplaced intracapsular fractures treated with internal fixation. They noted a nonunion rate of $6.4 \%$ and an osteonecrosis rate of $4.0 \%$. Age, walking ability, degree of impaction evident on an anteroposterior radiograph, and angulation on a lateral radiograph were determined to be predictive of healing complications. In this study, the conversion rate to arthroplasty was $7.7 \%$. $^{31}$

In their series of 1400 patients, Parker et al performed a cost-benefit analysis of various methods of treatment of hip fractures. The authors estimated a 30\% 1-year mortality rate for patients whose nondisplaced subcapital fractures were treated nonsurgically and who had an uneventful union. For those patients with displaced subcapital fractures, the authors predicted a $90 \% 1$-year mortality rate secondary to pneumonia, bedsores, and pulmonary emboli. ${ }^{32}$

\section{Displaced fractures}

The patient with a displaced femoral neck fracture is at significant risk for osteonecrosis and nonunion. Reported rates vary from $10 \%$ to $40 \% .^{33}$ Factors that determine the risk include age, displacement of fracture, and delay in operative fixation. ${ }^{34}$ Treatment options include closed reduction and internal fixation, open reduction and internal fixation (ORIF) with various devices, hemiarthroplasty (unipolar and bipolar), and total hip arthroplasty.

\section{Total hip arthroplasty versus ORIF}

Total hip arthroplasty as the primary operative procedure in elderly patients with a displaced hip fracture is becoming increasingly popular. Numerous reports have shown better functional and quality of life outcomes when compared with other modalities. ${ }^{35-37}$

Blomfeldt et al conducted a prospective randomized controlled trial in 102 patients (mean age 80 years) with displaced femoral neck fractures treated with either internal fixation or total hip arthroplasty. ${ }^{38}$ Outcomes measures included ability to perform activities of daily living, ability to live independently, health-related quality of life, complications, and revision surgery. At 2-year follow-up, the complication rate $(36 \%$ versus $4 \%, P<0.001)$ and revision rate ( $42 \%$ versus $4 \%, P<0.001)$ were significantly higher in the internal fixation group than in patients treated with total hip arthroplasty. Hip function in terms of quality of life $(P<0.05)$, comfort $(P<0.005)$, motion $(P<0.05)$, and walking ability $(P<0.05)$ were all significantly better in this group of independent, cognitively intact patients treated with total hip arthroplasty. At 4-year follow-up, the same investigators reported that the incidence of complications and revisions in the internal fixation group had increased but that no additional complications occurred and no revisions were required in the arthroplasty group.

Tidermark et al compared the outcomes of bipolar hemiarthroplasty and total hip arthroplasty in the treatment of displaced femoral neck fractures in a healthy, active, and alert elderly patient group. ${ }^{35}$ They concluded that the total hip arthroplasty group had better results and better functional outcome, with no increase in complication rates. They also reported no dislocations in their study.

Similar results were seen in a larger randomized controlled trial conducted by Rogmark et al who noted improved pain scores $(P<0.05)$ and walking ability $(P<0.05)$ in the total hip arthroplasty group. The mortality rate at 2-year follow-up was $21 \%$ for both groups, with a higher mortality rate among men versus women ( $33 \%$ versus $18 \%$, respectively). ${ }^{36}$

Johansson et al also found an increased rate of complications at 3-month and 1-year follow-up in patients with intact cognition who underwent internal fixation compared with total hip arthroplasty (54\% versus $22 \%$ ). In the same study, the authors concluded that complication and mortality rates were higher in patients with compromised mental status (57.7\% versus $12.7 \%$ ) compared with those having normal mental function. ${ }^{39}$

Ravikumar and Marsh performed a randomized controlled trial of 290 patients older than 65 years, comparing internal fixation, hemiarthroplasty, and total hip arthroplasty. At 13-year follow-up, revision rates were the lowest (6.75\%) and Harris hip scores were higher (80) in the patients who had undergone total hip arthroplasty. The internal fixation 


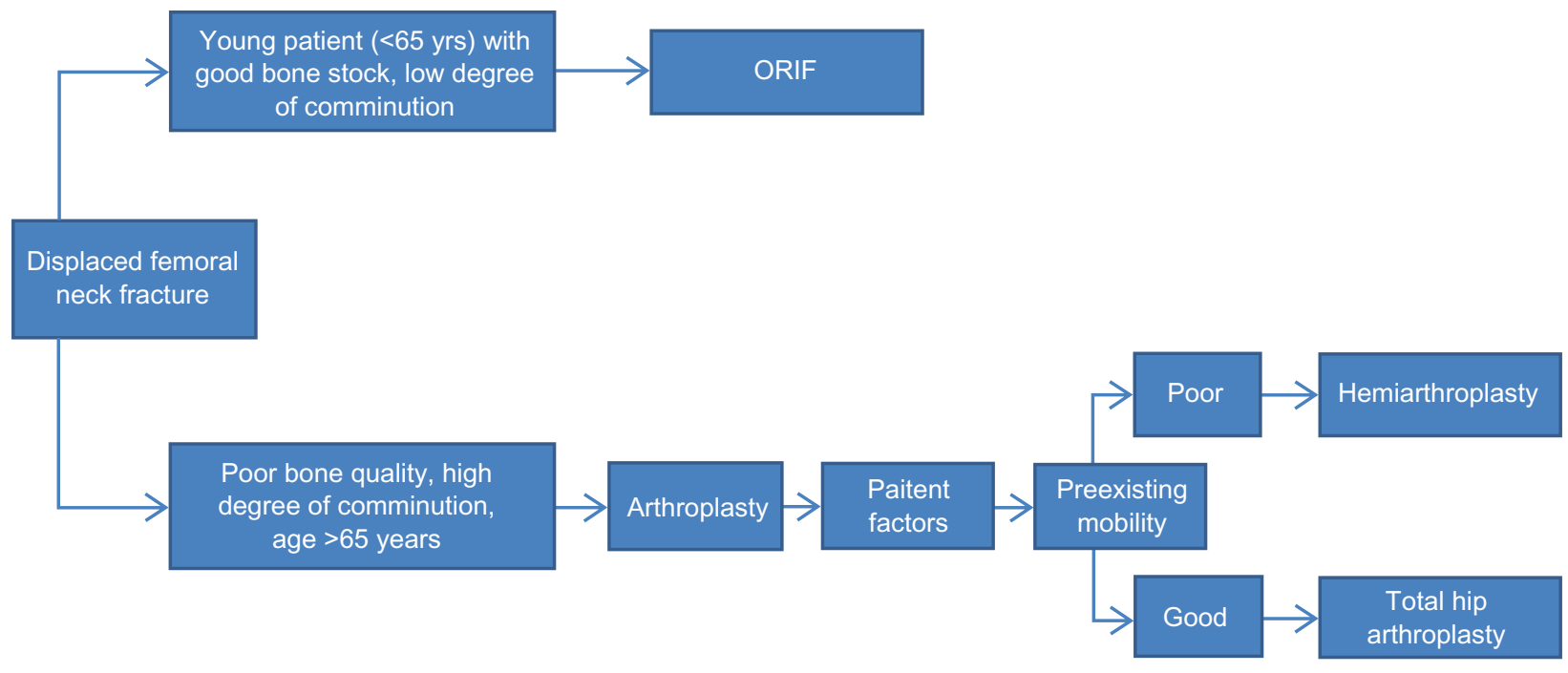

Figure I Algorithm for management of displaced fractures in the elderly.

Abbreviation: ORIF, open reduction and internal fixation.

and hemiarthroplasty groups had revision rates of $33 \%$ and $24 \%$, respectively. ${ }^{37}$

Skinner et al also randomized 278 patients to ORIF, hemiarthroplasty, or total hip arthroplasty for displaced femoral neck fractures. They showed equivalent mortality at 1 year postoperatively (25\%). The internal fixation group exhibited the highest revision rate $(25 \%)$. Pain relief and mobility were best in the total hip arthroplasty group. $^{40}$

A recent multicenter randomized controlled trial comparing internal fixation, hemiarthroplasty, and total hip arthroplasty in cognitively intact patients was performed by Keating et al. ${ }^{41}$ In total, 207 patients were recruited into the study comparing the three methods of treatment of displaced neck of femur fractures in healthy elderly patients. At 2-year follow-up, revision surgery was required in $39 \%$ of the internal fixation group, $5 \%$ of the hemiarthroplasty group, and $9 \%$ of the total hip arthroplasty group. The total hip arthroplasty group had significantly better functional outcome scores at 24 months as compared with the other two groups. Economic analysis of the data revealed that the internal fixation group was most costeffective in the acute fixation period, but the cost saving was eroded when subsequent admissions for revision were factored in.

Bhandari et al conducted a meta-analysis of all randomized controlled trials comparing internal fixation and arthroplasty reported over a 33-year period. Cumulative data showed a decreased rate of revision surgery in the arthroplasty group and an increased risk of infection. ${ }^{42}$ The relative risk of mortality in the arthroplasty group was higher during the first 4 months postoperatively but was no longer evident at 1 -year follow-up.

Reviewing the current literature, there is no consensus either supporting or rejecting the use of bipolar over unipolar hemiarthroplasty. ${ }^{43,44}$ The factors leading to increased acetabular cartilage erosion are age, associated osteoporosis, activity level, and length of follow-up. Unipolar hemiarthroplasty is generally recommended in older patients who are less active and have a shorter life expectancy. These patients would benefit least from the potential advantage of the more expensive bipolar prostheses. Compared with the unipolar prosthesis, bipolar prostheses have increased risk of polymer wear, dislocation requiring open reduction, and increased cost. The use of a bipolar prosthesis must be carefully evaluated when using it in elderly patients.

Bhandari et al in their paper reported that many surgeons felt that the short-term outcome following surgery was similar between the bipolar and total hip arthroplasty groups. ${ }^{45}$ However, reports do exist showing that the bipolar movement effect is lost and the device functions in a unipolar manner within 3-12 months post surgery. ${ }^{46}$

There has been much discussion about the complications following primary total hip arthroplasty, most notably an increased risk of dislocation, blood loss, and infections. Dislocation is a potentially disabling complication and reduces the quality of life for the patient. The increased dislocation rate for total hip arthroplasty in the fracture patient versus the elective arthritis patient has been attributed to increased range of motion. The rates of dislocation following total hip arthroplasty for fracture have ranged from $13 \%$ to $29 \%$ in patients who underwent a posterior approach..$^{37,39,41}$ Johanssen et al 


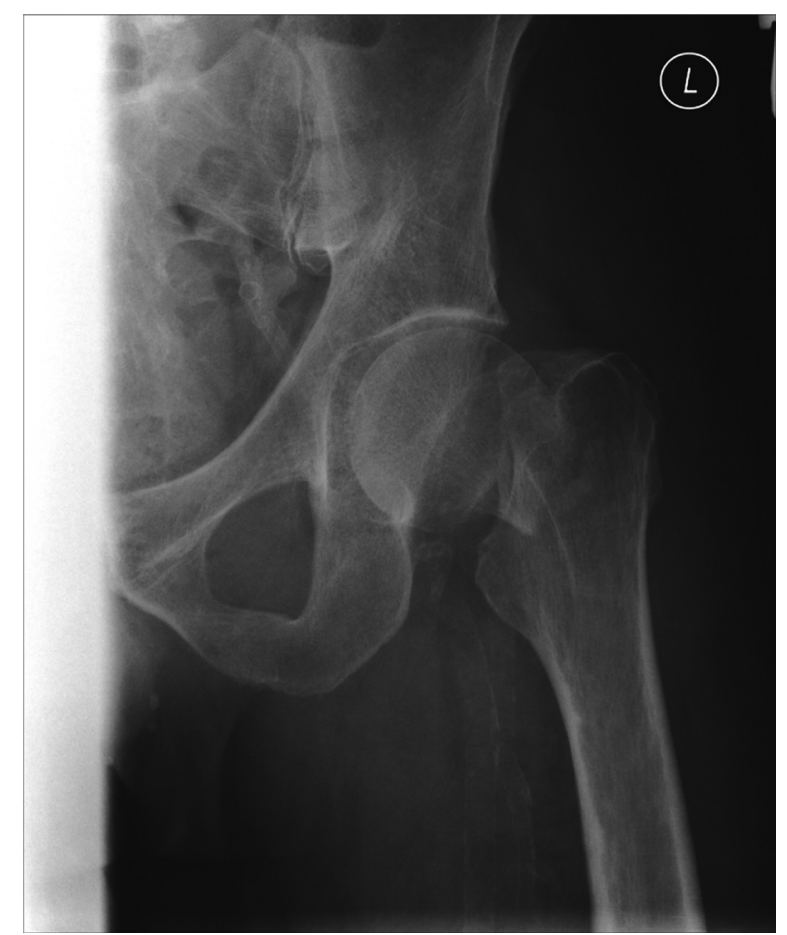

Figure 2 Displaced fracture neck of femur in an independently mobile 78 year old.

reported a dislocation rate of $32 \%$ in mentally impaired elderly patients compared with $12 \%$ in lucid patients. ${ }^{39}$

In their study of 120 patients, Blomfeldt et al report no dislocations following an anterolateral approach. ${ }^{38}$ Rogmark et al followed up 450 patients from the same institution and report no dislocations. ${ }^{36}$

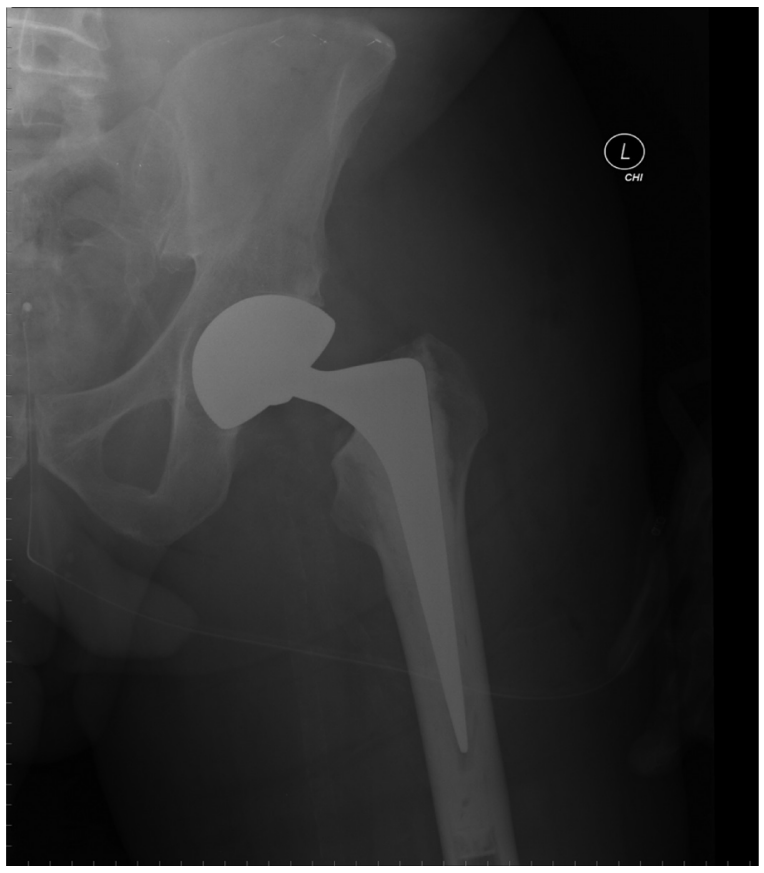

Figure 3 Immediate postoperative radiographs post total hip arthroplasty.
In their review of the Swedish hip registry, Leonardsson et al compared rates of revision between patients who underwent total hip arthroplasty for subcapital femoral neck fractures and those who underwent total hip arthroplasty for other reasons. ${ }^{47}$ They reported a $1.9 \%$ revision rate for dislocation in the fracture group compared with $0.7 \%$ in the other group. They also report that the risk of dislocation in the hips was 1.7 times higher when operated through the posterior approach.

Keene and Parker conducted a prospective study of 531 patients who underwent hemiarthroplasty with either an anterolateral or a posterior approach. ${ }^{48}$ The anterolateral approach was associated with increased surgical time ( 8 minutes longer), blood loss, and superficial infection (6\% versus $2.6 \%$ ). However, the report also indicated that the posterior approach was associated with a higher dislocation rate $(4.3 \%$ versus $1.7 \%)$ and more thromboembolic complications $(9.2 \%$ versus $1.3 \%)$. There was no difference in duration of hospital stay or mortality, and the authors suggested that surgeon comfort with the approach should dictate the exposure used.

Sierra et al reported no significant differences in dislocation rates between anterolateral, posterolateral, and transtrochanteric approaches in a series of 1812 bipolar hemiarthroplasties. ${ }^{49}$ The authors noted a total of only 32 dislocations, half of which occurred during the first 6 months postoperatively.

Varley and Parker performed a systematic literature review of dislocations and surgical approach over a 40 -year period. ${ }^{50}$ They found that the rate of dislocation with a posterior approach was $5.1 \%$ compared with $2.4 \%$ for an anterior approach.

A recent meta-analysis looking at 1669 patients from seven randomized controlled trials and eight retrospective cohort studies by Hopley et al showed that the risk of reoperation following a total hip arthroplasty is significantly lower compared with hemiarthroplasty at a minimum follow-up of 24 months. The pooled relative risk was 0.57 (95\% confidence interval [CI] 0.34-0.96), equaling a risk difference of $4.4 \%$ $(95 \%$ CI $0.2-8.0)$ in favor of total hip replacement. ${ }^{51}$

With increasing enthusiasm for treating femoral neck fractures with total hip arthroplasty, outcomes have been compared with those of patients undergoing this procedure for degenerative conditions. A retrospective study of 60 patients by Abboud et al showed no difference in outcomes for patients undergoing total hip arthroplasty for femoral neck fractures versus those undergoing the same procedure for osteoarthritis. ${ }^{52}$ Harris hip scores, perioperative morbidity, and mortality were equivalent for both groups. This is in contrast with earlier studies showing increased 
rates of dislocation in patients undergoing primary total hip arthroplasty for femoral neck fractures.

The longevity of total hip arthroplasty, especially in younger, more active patients, has been questioned. Greenough and Jones reviewed 37 patients (aged 70 years or younger) with no evidence of acetabular disease who were treated with primary total hip arthroplasty for subcapital femoral neck fracture. ${ }^{53}$ Of these, 18 patients (49\%) had undergone or were awaiting revision surgery at a mean follow-up of 56 months (range 12-112 months). The authors recommended against primary total hip arthroplasty for displaced femoral neck fracture in the younger patient without pre-existing hip disease.

Delamarter and Moreland reported on 27 patients with acute femoral neck fracture treated with total hip arthroplasty. ${ }^{54}$ At an average follow-up of 3.8 years, the authors reported complication rates to be less than in their elective total hip arthroplasty series. They reported no revision surgeries. Nineteen of the 27 patients had no pain and four patients had mild pain. Taine and Armour reported a series of 163 independently mobile patients older than 65 years who were treated with total hip arthroplasty for displaced femoral neck fracture. The reported revision rate was only $4 \%$ (seven of 163 hips). ${ }^{55}$ Both these studies concluded that total hip arthroplasty is the best treatment option for active patients with a longer life expectancy.

\section{Conclusion}

There are increasing reports of the use of total hip arthroplasty as a primary procedure for fractured neck of femur in healthy elderly patients. There is now significant evidence that older patients treated with hip arthroplasty have a better functional outcome and quality of life and fewer complications when compared with those undergoing internal fixation. The potential advantages of total hip arthroplasty must be considered against an increased initial cost and possibly a higher risk of dislocation and infection when compared with internal fixation.

\section{Disclosure}

The authors report no conflicts of interest in this work.

\section{References}

1. Felson DT, Anderson JJ, Hannan MT, Milton RC, Wilson PW, Keil DP. Impaired vision and hip fracture: The Framingham study. J Am Geriatr Soc. 1989;37:495-500.

2. Aharonoff GB, Koval KJ, Skovron ML, Zuckerman JD. Hip fractures in the elderly, predictors of one year mortality. J Orthop Trauma. 1997; 11:162-165.

3. Roberts SE, Goldacre MJ. Time trends and demography of mortality after fractured neck of femur in an English population, 1968-1998 Database study. BMJ. 2003;327:771-775.
4. Goldacre MJ, Roberts SE, Yeates D. Mortality after admission to hospital with fractured neck of femur: Database study. BMJ. 2002;325: 868-869.

5. Zuckerman JD. Hip fracture. N Engl J Med. 1996;334:1519-1525.

6. Stevens JA, Olson S. Reducing falls and resulting hip fractures among older women. MMWR Recomm Rep. 2000;49:3-12.

7. Kannus P, Parkkari J, Sievänen H, Heinonen A, Vuori I, Järvinen M. Epidemiology of hip fractures. Bone. 1996;18:S57-S63.

8. Singer BR, McLauchlan GJ, Robinson CM. Epidemiology of fractures in 15000 adults: The influence of age and gender. J Bone Joint Surg Br. 1998;80:243-248.

9. Kanis JA, Johnell O, Sembo I, et al. Long term risk of osteoporotic fracture in Malmo. Osteoporosis Int. 2000;11:669-674.

10. Anonymous. The prevention of falls in later life. A report of the Kellogg International Work Group on the prevention of falls by the elderly. Dan Med Bull. 1987;34:1-24.

11. Parkkari J, Kannus P, Heikkila J, Poutala J, Sievanen H, Vuori I. Energy shunting external hip protector attenuates the peak femoral impact force below theoretical fracture threshold: An in vitro biomechanical study under falling conditions of the elderly. J Bone Miner Res. 1995;10: 1437-1442.

12. Kannus P, Parkkari J, Poutala J. Comparison of force attenuation properties of four different hip protectors under simulated falling conditions in elderly: An in vitro biomechanical study. Bone. 1999;25:229-235.

13. Parker MJ, Gillespie LD, Gillespie WJ. Hip protectors for preventing hip fractures in the elderly. BMJ. 2006;332:571-574.

14. Kiel DP, Magaziner J, Zimmerman S, et al. Efficacy of a hip protector to prevent hip fracture in nursing home residents. The HIP PRO randomised control trial. JAMA. 2007;298:413-422.

15. Kannus P, Parkkari J, Niemi S, et al. Prevention of hip fracture in elderly people with use of hip protector. N Engl J Med. 2000;343:1506-1513.

16. Ray NF, Chan JK, Thamer M, Melton LJ III. Medical expenditure for treatment of osteoporotic fractures in United States in 1995: Report from National Osteoporosis Foundation. J Bone Miner Res. 1997;12:22-35.

17. Cummings SR, Rubin SM, Black D. The future of hip fractures in United States: Numbers, costs and potential effects of post menopausal oestrogen. Clin Orthop Relat Res. 1990;252:163-166.

18. Cox MA, Bowie R, Horne G. Hip fractures, an increasing health cost. J Orthop Trauma. 1993;7:52-57.

19. Tosteson AN, Burge RT, Marshall DA, Lindsay R. Therapies for treatment of osteoporosis in US women: Cost effectiveness and budget impact considerations. Am J Manag Care. 2008;14:605-615.

20. Burge RT, King AB, Balda E, Worley D. Methodology for estimating current and future burden of osteoporosis in state populations: Applications to Florida in 2000 through 2025. Value Health. 2003;6:574-583.

21. Burge R, Dawson-Hughes B, Solomon DH, Wong JB, King A, Tosteson A. Incidence and economic burden of osteoporosis related fractures in the United States, 2005-2025. J Bone Miner Res. 2007;22:465-475.

22. Frihagen F, Waaler GM, Madsen JE, Nordsletten L, Aspaas S, Aas E. Cost of hemiarthroplasty compared to internal fixation for femoral neck fractures. Acta Orthop. 2010;81:446-452.

23. Iorio R, Healy WL, Lemos DW, Appleby D, Lucchesi CA, Saleh KJ. Displaced femoral neck fractures in the elderly: Outcomes and cost effectiveness. Clin Orthop Rel Res. 2001;383:229-242.

24. Wheeless CR. Wheeless Textbook of Orthopaedics. Available at: http:// www.wheelessonline.com/ortho/avn_following_femoral_neck_fracture. Accessed 2010 Nov 1.

25. Huusko TM, Karppi P, Avikainen V, Kautiainen H, Sulkava R. Randomised clinically controlled trial of intensive geriatric rehabilitation of patients with hip fracture: Sub group analysis of patients with dementia. BMJ. 2000;321:1107-1111.

26. Vidan M, Serra JA, Moreno C, Riguelme G, Ortiz J. Efficacy of comprehensive geriatric intervention in older patients hospitalized for hip fracture: A randomised control trial. JAm Geriatr Soc. 2005;53: 1476-1482.

27. Binder EF, Brown M, Sinacore DR, Steger-May K, Yarasheski KE, Schechtman KB. Effect of extended outpatient rehabilitation following hip fracture. A randomised control trial. JAMA. 2004;292:837-846. 
28. Halberd J, Crotty M, Whitehead C, et al. Multi-disciplinary rehabilitation after hip fracture is associated with improved outcome. J Rehab Med. 2007;39:507-512.

29. McNamara I, Sharma A, Prevost T, Parker MJ. Symptomatic venous thromboembolism following hip fracture. Incidence and risk factors in 5300 patients. Acta Orthop. 2009;80:687-692.

30. Raaymakers EL, Marti RK. Non-operative treatment of impacted femoral neck fractures: A prospective study of 170 cases. J Bone Joint Surg Br. 1991;73:950-954.

31. Conn KS, Parker MJ. Undisplaced intracapsular hip fractures: Results of internal fixation in 375 patients. Clin Orthop Relat Res. 2004;421: 249-254.

32. Parker MJ, Myles JW, Anand JK, Drewett R. Cost-benefit analysis of hip fracture treatment. J Bone Joint Surg Br. 1992;74: 261-264.

33. Parker MJ, Raghavan R, Guruswamy K. Incidence of fracture healing complications after femoral neck fractures. Clin Orthop. 2007;458: 175-179.

34. Garden RS. Stability and union in subcapital fractures of the femur. J Bone Joint Surg Br. 1964;46:630-647.

35. Tidermark J, Ponzer S, Svensson O, Soderqvist A, Tornqvist H. Internal fixation compared to total hip replacement for displaced femoral neck fractures in the elderly, a randomised control trial. J Bone Joint Surg Br. 2003;85:380-388.

36. Rogmark C, Carlsson A, Johnell O, Sernbo I. Prospective randomised trial of internal fixation versus arthroplasty for displaced fractures of the neck of femur: Functional outcome for 450 patients at two years. J Bone Joint Surg Br. 2002;84:183-188.

37. Ravikumar KJ, Marsh G. Internal fixation versus hemiarthroplasty versus total hip replacement for displaced sub capital fractures of femur. 13 year results of prospective randomised study. Injury. 2003;31: 793-797.

38. Blomfeldt R, Törnkvist H, Ponzer S, Söderqvist A, Tidermark J. Comparison of internal fixation with total hip replacement for displaced femoral neck fractures: Randomized, controlled trial performed at four years. J Bone Joint Surg Am. 2005;87:1680-1688.

39. Johansson T, Jacobsson SA, Ivarsson I, Knutsson A, Wahlström O. Internal fixation versus total hip arthroplasty in the treatment of displaced femoral neck fractures: A prospective randomized study of 100 hips. Acta Orthop Scand. 2000;71:597-602.

40. Skinner P, Riley D, Ellery J, Beaumont A, Coumine R, Shafighian B. Displaced subcapital fractures of the femur: A prospective randomized comparison of internal fixation, hemiarthroplasty and total hip replacement. Injury. 1989;20:291-293.
41. Keating JF, Grant A, Masson M, Scott NW, Forbes JF. Randomized comparison of reduction and fixation, bipolar hemiarthroplasty, and total hip arthroplasty: Treatment of displaced intracapsular hip fractures in healthy older patients. J Bone Joint Surg Am. 2006;88:249-260.

42. Bhandari M, Devereaux PJ, Swiontkowski MF. Internal fixation compared with arthroplasty for displaced fractures of the femoral neck: A meta-analysis. J Bone Joint Surg Am. 2003;85:1673-1681.

43. Parker MJ, Guruswamy K. Arthroplasties (with and without bone cement) for proximal femoral fractures in adults. Cochrane Database Syst Rev. 2004;2:CD001706.

44. Raia FJ, Chapman CB, Herrera MF, Schweppe MW, Michelsen CB, Rosenwasser MP. Unipolar or bipolar hemiarthroplasty of femoral neck fractures in the elderly? Clin Orthop Relat Res. 2003;414:259-265.

45. Bhandari M, Devereaux PJ, Tornetta P III, et al. Operative management of displaced femoral neck fractures in elderly patients: An international survey. J Bone Joint Surg Am. 2005;87:2122-2130.

46. Phillips TW. The Bateman bipolar femoral head replacement: A fluroscopic study of movement over a four year period. J Bone Joint Surg Br. 1987;69:761-764.

47. Leonardsson O, Rogmark C, Karrholm J, Akesson K, Garellick G. Outcome after primary and secondary replacement for subcapital fracture of hip in 10264 patients. J Bone Joint Surg Br. 2009;91:595-600.

48. Keene GS, Parker MJ. Hemiarthroplasty of the hip: The anterior or posterior approach? A comparison of surgical approaches. Injury. 1993;24:611-613.

49. Sierra RJ, Schleck CD, Cabanela ME. Dislocation of bipolar hemiarthroplasty: Rate, contributing factors, and outcome. Clin Orthop Relat Res. 2006;442:230-238.

50. Varley J, Parker MJ. Stability of hip hemiarthroplasties. Int Orthop. 2004;28:274-277.

51. Hopley C, Stengel D, Ellernkamp A, Wich M. Primary total hip arthroplasty versus hemiarthroplasty for displaced intracapsular hip fractures in older patients: Systematic review. BMJ. 2010;340:C2332.

52. Abboud JA, Patel RV, Booth RE Jr, Nazarian DG. Outcomes of total hip arthroplasty are similar for patients with displaced femoral neck fractures and osteoarthritis. Clin Orthop Relat Res. 2004;421: $151-154$.

53. Greenough CG, Jones JR. Primary total hip replacement for displaced subcapital fracture of the femur. J Bone Joint Surg Br. 1988;70: 639-643.

54. Delamarter R, Moreland JR. Treatment of acute femoral neck fractures with total hip arthroplasty. Clin Orthop Relat Res. 1987;218:68-74.

55. Taine WH, Armour PC. Primary total hip replacement for displaced subcapital fractures of the femur. J Bone Joint Surg Br. 1985;67: 214-217.
Clinical Interventions in Aging

\section{Publish your work in this journal}

Clinical Interventions in Aging is an international, peer-reviewed journal focusing on evidence-based reports on the value or lack thereof of treatments intended to prevent or delay the onset of maladaptive correlates of aging in human beings. This journal is indexed on PubMed Central, MedLine, the American Chemical Society's 'Chemical

\section{Dovepress}

Abstracts Service' (CAS), Scopus and the Elsevier Bibliographic databases. The manuscript management system is completely online and includes a very quick and fair peer-review system, which is all easy to use. Visit http://www.dovepress.com/testimonials.php to read real quotes from published authors. 